\title{
A Critique on Baroreceptor and their Effective Reflex Action on Compartmental Cardiovascular Modeling in Regulating Hemodynamic Parameters
}

\author{
Sowparnika G C, Thirumarimurugan M, Vinoth N
}

\begin{abstract}
Baroreceptor is the feedback unit present in the living beings which acts as a sensor that is located in the walls of blood vessels. This sensor senses the deformation in the blood vessels which causes change in arterial blood pressure and regulates it via Central Nervous System (CNS) and the information are autonomic reflexes that has a great influence on circulatory system elements such as peripheral systemic resistance (Rpsym), contractility of the ventricles (Emax), unstressed volume of the ventricles (Vus_ven) and heart rate (HR). The dynamic behaviour of the baroreceptor is modeled and substantiated by applying the negative feedback mechanism. A detailed modeling and simulation study is presented considering various testing conditions in regulating the circulatory system elements which oversees the Mean Arterial Pressure (MAP) in cardiovascular system. The Total Artificial Cardiovascular model (TAH-CVS) is also developed using pressure, volume and flow related differential equations. Based on the testing conducted under various conditions, the feedback-mechanism of the baroreceptor model is combined with the continuous TAH-CVS closed loop model to validate the effectiveness of the baroreceptor model. The simulation results of TAH-CVS model at initial conditions are compared with the TAH-CVS model with baroreceptor.
\end{abstract}

Keywords : Circulatory system, closed loop, hear, feedback, nerve activity, testing.

\section{INTRODUCTION}

There are several feedback loops present in the human body for maintaining hormone levels, blood sugar, temperature, $\mathrm{pH}$ and blood pressure. The control mechanism that shows an immediate effect in regulating the blood pressure is baroreceptor whereas the other mechanisms namely humoral, renal and tissue regulations are deliberate [1-4]. The feedback actions taken by baroreceptor are autonomic reflexes that

Revised Manuscript Received on December 30, 2019.

* Correspondence Author

Sowparnika G C*, Department of Chemical Engineering, Coimbatore Institute of Technology, Coimbatore, India.

Thirumarimurugan M, Department of Chemical Engineering, Coimbatore Institute of Technology, Coimbatore, India.

Vinoth N, Department of Instrumentation Engineering, Madras Institute of Technology, Chennai, India.

(C) The Authors. Published by Blue Eyes Intelligence Engineering and Sciences Publication (BEIESP). This is an open access article under the CC BY-NC-ND license (http://creativecommons.org/licenses/by-nc-nd/4.0/) have influence in change of sympathetic nerve activity of the cardiovascular system [5], [6].

Baroreceptor usually receives change in arterial pressure through mechanical distortion and deformation of the blood vessels [7]. This causes change in $\mathrm{R}_{\text {sys }}, \mathrm{E}_{\max }, \mathrm{V}_{\text {us_ven }}$ and $\mathrm{HR}$. The baroreflexes are then transferred to CNS. The CNS generates nervous activities in two ways such as sympathetic and parasympathetic. The neural activities are transferred by the efferent part to change the $\mathrm{R}_{\text {sys }}, \mathrm{E}_{\max }, \mathrm{V}_{\text {us_ven }}$ and HR. The afferent part contains the receptor which provides nerve activity based on the change in arterial pressure. Based on the changes in these parameters, the arterial blood pressure is regulated, the action if baroreceptor is increased initially and is then transformed over time as the arterial pressure reached nominal value. This is justified by applying the baroreceptor model as the feedback system to the TAH-CVS model and their simulation results are compared.

\section{MATERIALS AND METHODS}

\section{A. Baroreceptor Model}

Baroreceptor is stretch receptor situated on the walls of the blood vessels, the most approachable of which are located in aortic arch and in the carotid sinus. Carotid sinus baroreceptor is situated commonly in the particular part of the two carotid sinus arteries [8] Aortic arch baroreceptor on the other hand, is situated on the walls of the aortic arch. The carotid sinus and aortic arch receptors are assumed to be functionally similar, expect that the operating condition of aortic arch receptor is at a higher pressure level [9-11]. The baroreceptor modeled here is concentrated on the carotid sinus which has nerve ending and respond to deformation in the walls of the blood vessels as shown in Fig. 1.

The nerve activity develops from two sections, a pressure-mechanical and electro-mechanical component [12]. The carotid sinus receptor produces nerve activity which are called firing rates. The baroreceptor acts immediately to irregularities in the walls of blood vessel by a pressure-mechanical mechanism [13], [14]. The electro-mechanical component generates the baroreceptor firing rate by the electro-mechanical mechanism inbuilt in the receptor. The cardio inhibitory and vasomotor center of the CNS generates sympathetic nerve activity [15]. The efferent pathway transmits the nerve activity to the TAH-CVS model. The input function to the baroreceptor model is expressed in Eq. (1) [16], [17]. 
The parameters that are influenced by autonomic reflexes are modeled in such a way that it provides continuous control action to regulate the MAP as shown in Eq. (2)-(5). The nominal values such as $M A P_{\text {nom }}, R_{\text {psymbase }}$, Els max base,$V_{\text {us_ven base }}$ and $H R_{\text {base }}$ discussed in Eq. (1)-(5) are shown in Table 1.

\section{B. Baroreceptor with Cardiovascular Model}

The neural activity transmitted from the CNS causes rapid modification in $R_{\text {psym }}, E l s_{\max }, V_{u_{\text {s }} \text { ven }}$ and $H R$. These stimuli are given as the feedback signal to the TAH-CVS model [18], [19]. The TAH-CVS model is a four compartment model namely left heart, systemic circulatory system, right heart and pulmonary circulatory system. The continuous process of TAH-CVS model is simulated with MAP input from the baroreceptor model.

In this model, the left and right heart is partitioned into two atrial parts and three ventricular parts. When the left ventricular pressure exceeds the systemic aortic pressure, the aortic valve opens and the blood enters into systemic circulation through peripheral systemic resistance $R_{\text {psym }}$. The veins return the blood to right atrium. When the right atrial pressure exceeds right ventricular pressure, the tricuspid valve opens and the blood enters into right ventricle [20], [21]. When the right ventricular pressure exceeds the pulmonary aortic pressure, the blood enters into pulmonary circulation through pulmonary valve. The veins return the blood to left atrium. When the left atrial pressure exceeds the left ventricular pressure, the blood enters into left ventricle by the opening of mitral valve. In this way, the TAH-CVS is modeled which represents the continuous closed loop system. The modeling equations are classified based on the relationship between pressure, volume and flow as shown in Eq. (6)-(8).

The Cardiovascular modeling is carried out by compartmental approach with six main compartments such as left heart, right heart, systemic circulation, systemic veins, pulmonary circulation and pulmonary veins as shown in Eq. (9)-(50).

\section{Left Heart}

The equations representing left heart is expressed in Eq. (9)-(17).

\section{Right Heart}

The equations representing left heart is expressed in Eq. (18)-(26).

\section{E. Systemic circulation}

The systemic circulatory system is further sub classified into three arterial sections and two venous sections as shown in Eq. (27)-(38).

\section{F. Pulmonary Circulation}

The pulmonary circulatory system is further sub classified into three arterial sections and two venous sections as shown in Eq. (39)-(50).

\section{RESULTS AND DISCUSSION}

Following the modeling of baroreceptor and TAH-CVS model, the baroreceptor model is tested by varying the MAP values within the range of $30-140 \mathrm{mmHg}$. The MAP inputs to the baroreceptor model provided wide range of values for the circulatory system parameters shown in Table 2.

The values obtained from Table 2 are then specified in the TAH-CVS model and the effective reflex actions by the baroreceptor are shown in Fig. 2 -9 which shows that baroreceptor model is dynamic and provides rapid action. Usually the peripheral systemic resistance, maximum elastance and heart rate decreases with increase in MAP, hence they are inversely proportional. On other hand, unstressed ventricular volume increases with increase in MAP and implies to be directly proportional. This condition is proved in Fig. 2-5 and the obtained circulatory system parameters are implemented in the TAH-CVS model to test for the dynamics of baroreceptor model and their results are shown in Fig. 6-9.

Based on the testing conducted under various conditions, the feedback-mechanism of the baroreceptor model is combined with the continuous TAH-CVS closed loop model to validate the effectiveness of the baroreceptor model and their rapid action to the change in MAP. The simulation results of TAH-CVS model at initial conditions are compared with the TAH-CVS model with baroreceptor in Fig. 10-11. These results imply that the baroreceptor plays a major role in auto regulation of MAP.

From the Fig. 10-11, it is seen that the MAP value is having a peak of about 200/110 mmHg which is immediately regulated to $160 / 99 \mathrm{mmHg}$ by baroreceptor feedback mechanism. In this way, baroreceptor helps to regulate the mean arterial blood pressure (MAP) in a closed loop feedback control mechanism. The nominal value of MAP endured around $99 \mathrm{mmHg}$ in TAH-CVS model without baroreceptor mechanism. When the baroreceptor model was implemented along with TAH-CVS model and simulated, the automatic feedback mechanism took place and the nominal value of MAP was lowered to $92 \mathrm{mmHg}$. Thus crucial role of baroreceptor is henceforth proved as shown in Fig. 12.

\section{CONCLUSION}

Thus the dynamic baroreceptor model is developed with TAH-CVS model which helps in initial study on the hemodynamic parameters since conducting trial run or tests on living subjects involves various legal issues. The variations in the MAP make the baroreceptor model to take an immediate feedback action to regulate the mean arterial pressure until the nominal range is obtained. Furthermore, the work is extended to study the baroreceptor and TAH-CVS model mechanisms for the drug model by varying drug input actions of Sodium Nitroprusside and Dopamine.

\section{APPENDIX}

$B F C_{\text {in }}=\frac{\exp ^{\alpha\left(M A P-M A P_{\text {HOW }}\right)}}{1+\exp }$

Where $M A P_{\text {nom }}$ is the nominal value of MAP and $\alpha$ is the constant.

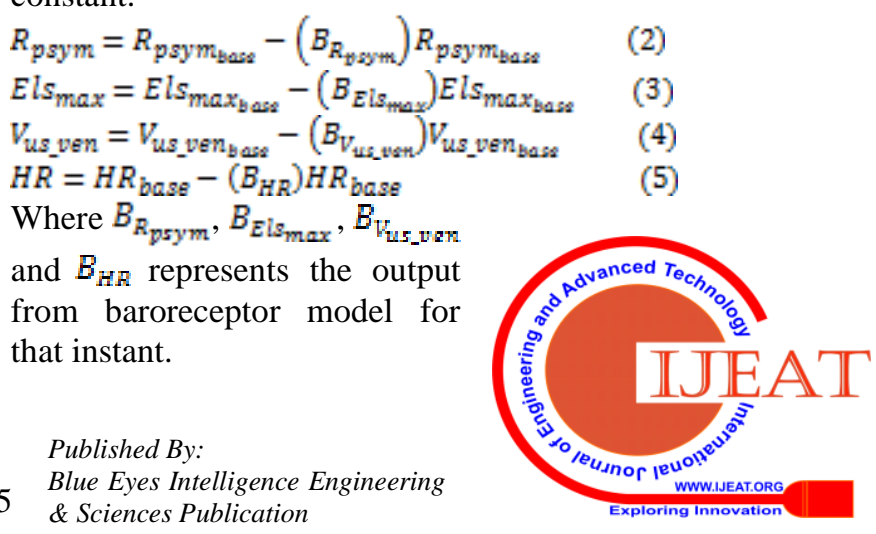




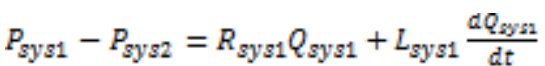

$\frac{a V_{\mathrm{WHn}}}{d t}=Q_{\mathrm{lv}}-Q_{\mathrm{sys}}$

$P_{\text {sysi1 }}=\frac{1}{C_{\text {wan }}}\left(V_{\text {sysi1 }}-V_{\text {ugsysi1 }}\right)$

Where $P_{s y s 1}$ and $P_{s y s 2}$ are the aortic systemic pressure in partition 1 and partition 2. $R_{s y s 1}$ represents viscosity, $L_{\text {sys } 1}$ represents inertia and $C_{\text {sys } 1}$ represents elastance properties, $Q_{s y s 1}$ and $V_{s y s 1}$ represents flow and volume and $V_{u s}$ represents unstressed volume.

C. Left Heart

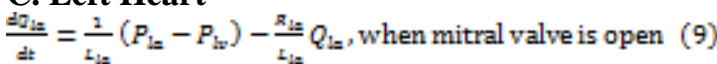

$Q_{\mathrm{h}}=0$, when mitral walwe is closed

$\frac{d V_{L E}}{d t}=Q_{\mathrm{lz}}-Q_{\mathrm{L}}$

$P_{l=}=E_{l a}\left(V_{l k}-V_{d l a}\right)$

where $Q_{\text {la }}$ is flowrate of left atria

$L_{\text {१a }}$ is inertial vessel properties of left atria

$P_{\text {la }}$ is left atrial pressure

$P_{l v}$ is left ventricular pressure

$R_{\text {la }}$ is resistance of left atria

$V_{l a}$ is volume of left atria

$Q_{12}$ is flowrate of pulmonary venous section2

$E_{l a}$ is elastance of left atria

$V_{d l a}$ is volume of left atria at zero pressure

D. Right Heart

$\frac{\mathrm{dQ}_{\mathrm{lV}}}{\mathrm{dt}}=\frac{1}{\mathrm{~L}_{\mathrm{lv}}}\left(\mathrm{P}_{\mathrm{lV}}-\mathrm{P}_{\mathrm{gS}}\right)$, when aortic valve is open

$Q_{\mid y}=0$, when aortic valve is closed

$\frac{d V_{l v}}{d t}=Q_{l a}-Q_{l v}$

$P_{l v}=E_{l v}\left(V_{l v}-V_{d i v}\right)$

$P_{a g}=R_{0 s} Q_{i v}+P_{a 1}$

where $Q_{i v}$ is left ventricular flowrate

$L_{i v}$ is inertial vessel properties of left ventricle

$P_{l v}$ is left ventricular pressure

$P_{a g}$ is systemic aortic pressure

$V_{l v}$ is left ventricular volume

$E_{l v}$ is elastance of left ventricle

$V_{d i v}$ is left ventricular volume at zero pressure

$R_{\text {og }}$ is systemic resistance

$P_{a 1}$ is pressure at systemic arterial section 1

E. Systemic Circulation

$\frac{d Q_{r s}}{d t}=\frac{1}{L_{r s}}\left(P_{r=}-P_{r w}\right)-\frac{R_{r s}}{L_{r z}} Q_{r s}$, when tricuspid walve is open

$Q_{\text {ra }}=0$ when tricuspid valve is closed

$\frac{d V_{r a}^{a}}{d t}=Q_{r 2}-Q_{r a}$

$P_{\mathrm{ra}}=E_{\mathrm{ra}}\left(V_{\mathrm{ra}}-V_{d r a}\right)$

where $Q_{r a}$ is flowrate of right atria

$L_{r a}$ is inertial vessel properties of right atria

$P_{r a}$ is lright atrial pressure

$P_{r v}$ is right ventricular pressure

$R_{r a}$ is resistance of right atria

$V_{r a}$ is volume of right atria

$Q_{r 2}$ is flowrate of pulmonary arterial section2

$E_{r a}$ is elastance of right atria

$V_{d r a}$ is volume of right atria at zero pressure

$\frac{\mathrm{dQ} \mathrm{rv}}{\mathrm{dt}}=\frac{1}{\mathrm{~L}_{\mathrm{rv}}}\left(\mathrm{P}_{\mathrm{rV}}-\mathrm{P}_{\mathrm{ap}}\right)$, when pulmonary valve is open (22)

$Q_{Y v}=0$, when pulmonary valve is closed (23)

$\frac{\mathrm{d} \mathrm{V}_{\mathrm{rv}}}{d t}=Q_{\mathrm{ra}}-Q_{\mathrm{rv}}$

$P_{r v}=E_{r v}\left(V_{r v}-V_{d r v}\right)$

$P_{\text {ap }}=R_{\text {op }} Q_{r v}+P_{p 1}$ where $Q_{r v}$ is right ventricular flowrate

$L_{r v}$ is inertial vessel properties of right ventricle

$P_{r y}$ is right ventricular pressure

$P_{a p}$ is aortic pulmonary pressure

$V_{r v}$ is rightventricular volume

$E_{r v}$ is elastance of right ventricle

$V_{d v v}$ is right ventricular volume at zero pressure

$R_{\text {op }}$ is pulmonary resistance

$P_{\text {p1 }}$ is pressure at pulmonary arterial section 1 Arterial section 1

$\frac{d Q_{a 1}}{d t}=\frac{1}{L_{a 1}}\left(P_{a 1}-P_{a 2}\right)-\frac{R_{a 1}}{L_{a 1}} Q_{a 1}$
$\frac{d V_{a 1}}{d t}=Q_{i v}-Q_{a 1}$
$P_{a 1}=\frac{1}{C_{a 1}}\left(V_{a 1}-V_{u n a 1}\right)$

Arterial section 2

$\frac{d V_{a 2}}{d t}=Q_{a 1}-\frac{\left(P_{a 2}-P_{a 31}\right)}{R_{a 2}}$

$P_{a 2}=\frac{1}{C_{a 2}}\left(V_{a 2}-V_{u n a 2}\right)$

$\frac{d V_{a a}}{d t}=\frac{\left(P_{a 2}-P_{a a}\right)}{R_{a 2}}-\frac{\left(P_{a a}-P_{a 1}\right)}{R_{a a}}$

$P_{a \mathrm{a}}=\frac{1}{C_{a \mathrm{a}}}\left(V_{a \mathrm{a}}-V_{\text {unaa }}\right)$

where $Q_{a 1}$ is the flowarte of arterial section 1

$R_{a x}, R_{a z}, R_{a x}$ are the viscoscity of arterial sections 1,2 and 3

$C_{a 12} C_{n z 2} C_{n z}$ are the elastic properties of arterial sections 1,2 and 3

$L_{a 1}$ is the inertial vessel properties of arterial section1

$P_{a 2}, P_{a a}$ are the pressure at arterial sections 2 and 3

$V_{a 1}, V_{a 2}, V_{a 2}$ are the volume of arterial sections 1,2 and 3

$V_{\text {una1 }}$ is the volume of arterial section 1 at zero pressure

$V_{\text {unad }}$ is the volume of arterial section 3 at zero pressure

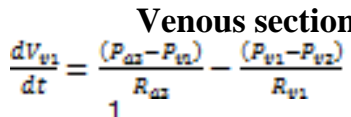

$P_{V 1}=\frac{1}{C_{V 1}}\left(V_{V 1}-V_{\text {wnV1 }}\right)$

Venous section 2

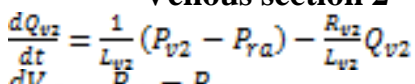

$\frac{d V_{V 2}}{d t}=\frac{P_{V 1}-P_{V 2}}{R_{V 1}}-Q_{v 2}$

$P_{\mathrm{v} 2}=\frac{1}{C_{\mathrm{v} 2}}\left(V_{\mathrm{v} 2}-V_{\mathrm{wnv2}}\right)$

where $Q_{v 2}$ is the flowarte of venous section 1

$R_{\mathrm{V} 1}, R_{\mathrm{V} 2}$ are the viscoscity of venous sections 1 and 2

$C_{\mathrm{V} 1}, C_{\mathrm{V} 2}$ are the elastic properties of venous sections 1 and 2

$L_{\mathrm{W} 2}$ is the inertial vessel properties of venous section2

$P_{\mathrm{V} 1}, P_{\mathrm{V} 2}$ are the pressure at venous sections 1 and 2

$V_{\mathrm{V} 1}, V_{\mathrm{V} 2}$ are the volume of venous sections 1 and 2

$V_{\text {WW1 }}$ is the volume of venous section 1 at zero pressure

$V_{\text {und }}$ is the volume of venous section 2 at zero pressure

F. Pulmonary Circulation

Arterial section 1

$\frac{a Q_{\mathrm{H} 1}}{d t}=\frac{1}{L_{\mathrm{L} 1}}\left(P_{\mathrm{p} 1}-P_{\mathrm{p} 2}\right)-\frac{\mathbb{R}_{\mathrm{H} 12}}{L_{\mathrm{H} 1}} Q_{\mathrm{p} 1}$

$\frac{d V_{p 1}}{d t}=Q_{r v}-Q_{p 1}$

$P_{p 1}=\frac{1}{C_{p 1}}\left(V_{p 1}-V_{u n p 1}\right)$

$\frac{d V_{p 2}}{d t}=Q_{p 1}-\frac{\begin{array}{c}\text { Arterial section } 2 \\ \left(P_{p 2}-P_{p a}\right)\end{array}}{R_{p 2}}$

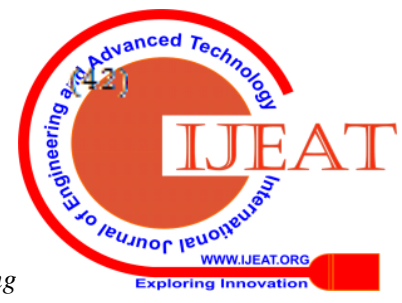


$P_{p 2}=\frac{1}{C_{p 2}}\left(V_{p 2}-V_{\text {unp2 }}\right)$

$\frac{d V_{\mathrm{pa}}}{d t}=\frac{\left(P_{\mathrm{p} 2}-P_{\mathrm{pa} a}\right)}{R_{\mathrm{a} 2}}-\frac{\left(P_{\mathrm{pa}}-P_{\mathrm{i1}}\right)}{R_{\mathrm{ab}}}$

$P_{a a}=\frac{1}{C_{p a}}\left(V_{p a}-V_{\text {unpa }}\right)$

where $Q_{p 1}$ is the flowarte of pulmonary section 1

$R_{\mathrm{p} 1}, R_{\mathrm{p} 2}, R_{\mathrm{pa}}$ are the viscoscity of pulmonary sections 1,2 and 3

$C_{\mathrm{w} 12} C_{\mathrm{yz}} C_{\mathrm{yz}}$ are the elastic properties of pulmonary sections $1_{3} 2$ and 3

$L_{\mathrm{p} 1}$ is the inertial vessel properties of pulmonary section 1

$P_{p 2}, P_{p a}$ are the pressure at pulmonary sections 2 and 3

$V_{p 1}, V_{p 2}, V_{p a}$ are the volume of pulmonary sections $1_{x} 2$ and 3

$V_{\text {unp } 1}$ is the volume of pulmonary section 1 at zero pressure

$V_{\text {unpa }}$ is the volume of pulmonary section 3 at zero pressure

\section{Venous section 1}

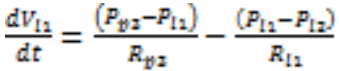

$P_{l 1}=\frac{1}{C_{l 1}}\left(V_{l 1}-V_{\text {uni1 }}\right)$

Venous section 2

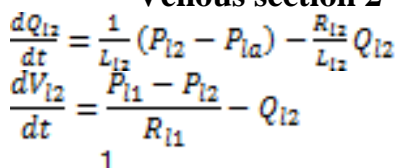

$P_{12}=\frac{1}{C_{i 2}}\left(V_{12}-V_{\text {uni2 }}\right)$

where $Q_{12}$ is the flowarte of venous section 1

$R_{11}, R_{12}$ are the viscoscity of venous sections 1 and 2

$C_{11}, C_{i 2}$ are the elastic properties of venous sections 1 and 2

$L_{72}$ is the inertial vessel properties of venous section 2

$P_{l 1}, P_{l 2}$ are the pressure at venous sections 1 and 2

$V_{11}, V_{l 2}$ are the volume of venous sections 1 and 2

$V_{\text {wnl1 }}$ is the volume of venous section 1 atzero pressure

$V_{\text {wni2 }}$ is the volume of venous section 2 atzero pressure

\section{REFERENCES}

1. Albaghdadi .M, "Baroreflex control of long-term arterial pressure", Revista Brasileira de Hipertens, vol.14, pp. 212-225, 2007.

2. $\quad$ Barett .C, Malpas .S.C, "Problems, possibilities and pitfalls in studying the arterial baroreflexes influence over long-term control of blood pressure", American Journal of Physiology Regulatory, Integrative and Comparative Physiology , vol. 288: R837-R845, 2005.

3. Bertinieri .D, Di Rienzo .M, Cavallazzi .A, Ferrari .A.U, Pedotti .A Mancia .G, "Evaluation of baroreceptor reflex by blood pressure monitoring in unanesthetized cats", American Journal of Physiology, vol. 254, pp.H377-H383, 1988.

4. Brown .A, "Receptor under pressure: An update on baroreceptors", Circulation Research, vol. 46, pp.1-10, 1980.

5. Chapleau .M.W, Abboud .F.M, "Modulation of baroreceptor activity", Brazilian Journal of Medical and Biological Research , vol.27, 1994.

6. Davos .C.H, Davies .L.C, Piepoli .M, "The Effect of Baroreceptor Activity on Cardiovascular Regulation", Hellenic Journal of Cardiology, vol.43, pp.145-55, 2002.

7. Esler .M, Jennings .G, Korner .P, Willett .I, Dudley .F, Hasking .G, Anderson .W, Lambert .G, "The assessment of human sympathetic nervous system activity from measurement of norepinephrine turnover", Hypertension, vol.11, pp.3-20, 1998.

8. Farrell .T.G, Paul .V, Cripps .T.R, Malik .M, Bennett .E.D, Ward .D, Camm .A.J, "Baroreflex sensitivity and electrophysiological correlates in patients after acute myocardial infarction", Circulation, vol.83, pp. 945-952, 1991
9. Grassi .G, Cattaneo .B.M, Seravalle .G, Lanfranchi .A, Mancia .G, "Baroreflex control of sympathetic nerve activity in essential and secondary hypertension", Hypertension, vol.31, pp.68-72, 1998.

10.Hajduczok .G, Chapleau .M.W, Abboud .F.M, "Rapid adaptation of central pathways explains the suppressed baroreflex with aging", Neurobiology of Aging, vol.12, pp.601-604, 1991.

11.Hasser .E.M, Cunningham .J.T, Sullivan .M.J, Curtis .K.S, Blaine .E.H, Hay .M, "Area Postrema and Sympathetic Nervous System Effects of Vasopressin and Angiotensin II", Clinical and Experimental Pharmacology and Physiology, vol.27, pp.432-436, 2000.

12.McCubbin .J.W, Green .J.H, Page .I.H, "Baroreceptor function in chronic renal hypertension”, Circulation Research, vol.4, pp.205-210, 1956.

13.Ninomiya, Nisimaru .N, Irisawa .H, "Sympathetic nerve activity to the spleen, kidney and heart in response to baroreceptor input", American Journal of Physiology, vol. 221, pp.1346-1351, 1971.

14.Ohuchi .H, Suzuki .H, Toyohara .K, Tatsumi .K, Ono .Y, Arakaki .Y, Echigo .S, "Abnormal cardiac autonomic nervous activity after right ventricular outflow tract reconstruction", Circulation, vol.102, pp.2732-2738, 2000.

15.Ottesen .J.T, "Modelling the Dynamical Baroreflex-Feedback Control", Mathematical and Computer Modelling, vol.31, pp.167-173, 2000.

16.Schreiner .G, Berglund .E, Borst .H, Monroe .R, "Effects of vagus stimulation and of acetylcholine on myocardial contractility, $\mathrm{O}_{2}$ consumption and coronary flow in dogs", Circulation Research, vol. 5 , pp. 562-567, 1957.

17.Heldt .T, Eun .B.S, Roger .D.K, Roger .G.M, “Computational Modeling of Cardiovascular Response to Orthostatic Stress", Journal of Applied Physiology, vol.92, pp.1239-1254, 2002.

18.Lu .K, Clark .J.W, Ghorbel .F.H, Ware .D.L, Bidani .A, “A Human Cardiopulmonary System Model applied to the analysis of the ValsalvaManerver", American Journal of Physiology, vol. 281, pp. H2661-H2679, 2001.

19.Podnar .T, Runovc .F, Kordas .M, "Simulation of cardiovascular physiology: the diastolic function(s) of the heart", Computers in Biology and Medicine, vol.32, pp.363-377, 2002.

20.Rupnik .M, Runovc .F, Sket .D, Kordas .M, "Cardiovascular physiology: Simulation of steady state and transient phenomena by using the equivalent electronic circuit", Computer Methods and Programs in Biomedicine, vol. 67, pp.1-12, 2002.

21.Schreiner .G, Berglund .E, Borst .H, Monroe .R, "Effects of vagus stimulation and of acetylcholine on myocardial contractility, $\mathrm{O}_{2}$ consumption and coronary flow in dogs", Circulation Research, vol.5, pp.562-567, 1957.

\section{AUTHORS PROFILE}

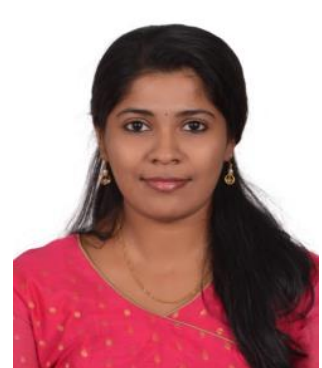

G.C.Sowparnika was born in Coimbatore. She received her B.E degree in Electronics and Instrumentation Engineering in Sri Ramakrishna Engineering College, Coimbatore, Anna University, Tamil Nadu, India in 2014, M.Tech., in Process Dynamics and Control at Coimbatore Institute of Technology, Coimbatore, Tamil Nadu, India. and Doctorate from Coimbatore Institute of Technology, Coimbatore, Tamil Nadu, India. Her area of interests are control systems, process control, physiological modeling and bioengineering. 


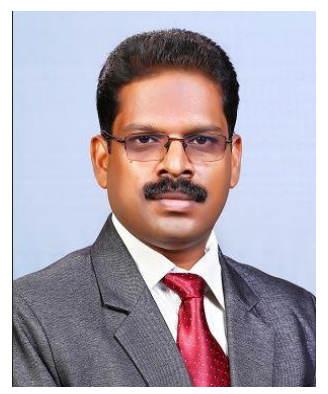

Dr.M.Thirumarimurugan is currently working as Professor and Head of the Department in Chemical Engineering, Coimbatore Institute of Technology, Coimbatore, Tamil Nadu, India. He obtained both his Bachelors and Masters Degree in Chemical Engineering from Bharathiar University. After his B.Tech., he served as Lecturer in Erode Institute of Chemical Technology (EICT) in 1995. Later, he joined Coimbatore Institute of Technology (CIT) as Lecturer in Chemical Engineering Department in the same year. His area of interest are Modelling, Simulation and Performance Analysis of Heat Exchangers.

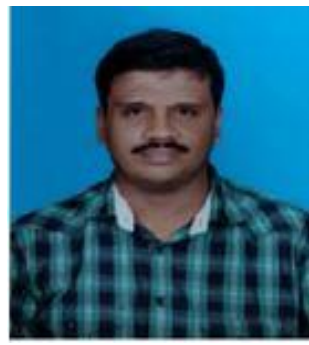

Dr.N.Vinoth is currently working as Assistant Professor in Madras Institute of Technology, Chennai, India. He has completed his Bachelor in Engineering in Electronics and Instrumentation Engineering from Annamalai University in 2002, M.E in Process Control and Instrumentation from Annamalai University in 2007 and Doctorate in Instrumentation from Annamalai University in 2015. He has teaching experience of about 16 years and his area of interest includes instrumentation, bioengineering and process control.

\section{Figures}

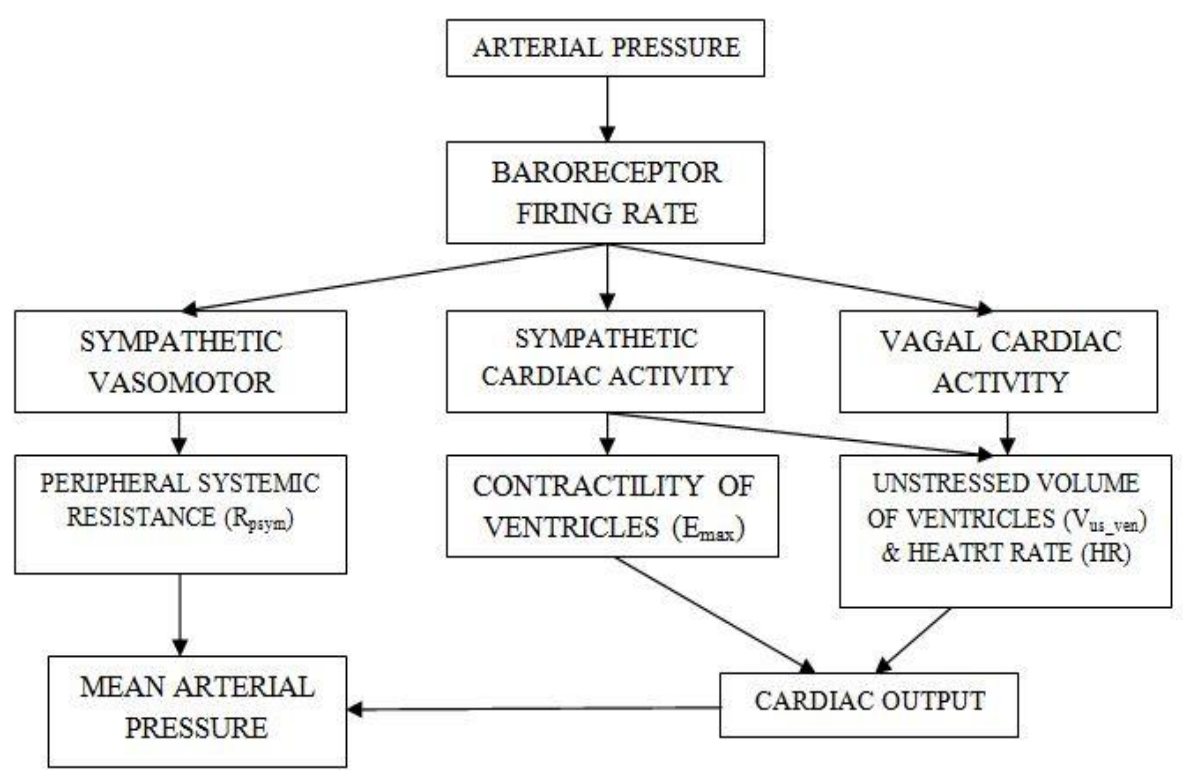

Fig. 1 Schematic representation of baroreceptor 
A Critique on Baroreceptor and their Effective Reflex Action on Compartmental Cardiovascular Modeling in Regulating Hemodynamic Parameters

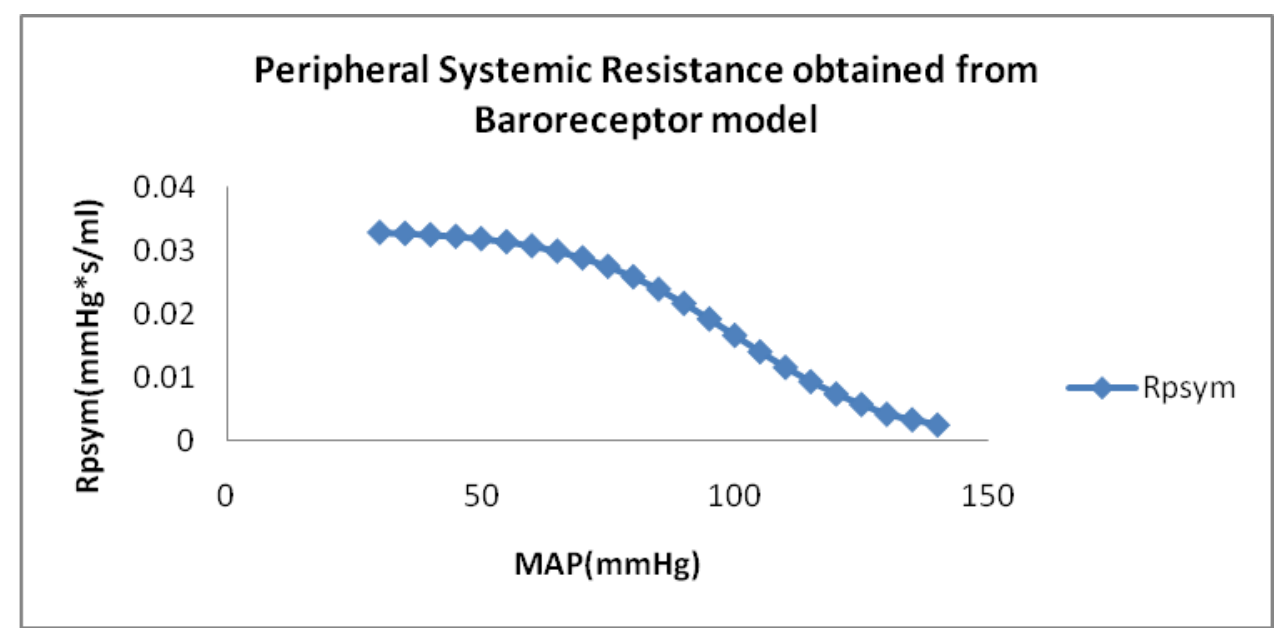

Fig. $2 \mathbf{R}_{\text {psym values obtained from baroreceptor model for various MAP }}$

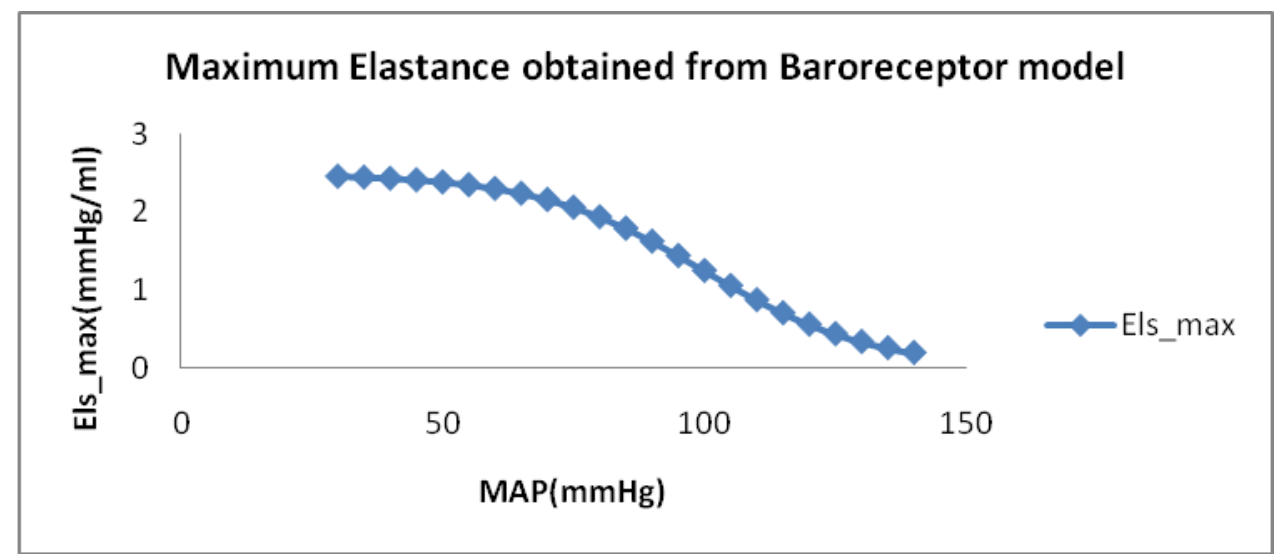

Fig. 3 Elsmax values obtained from baroreceptor model for various MAP

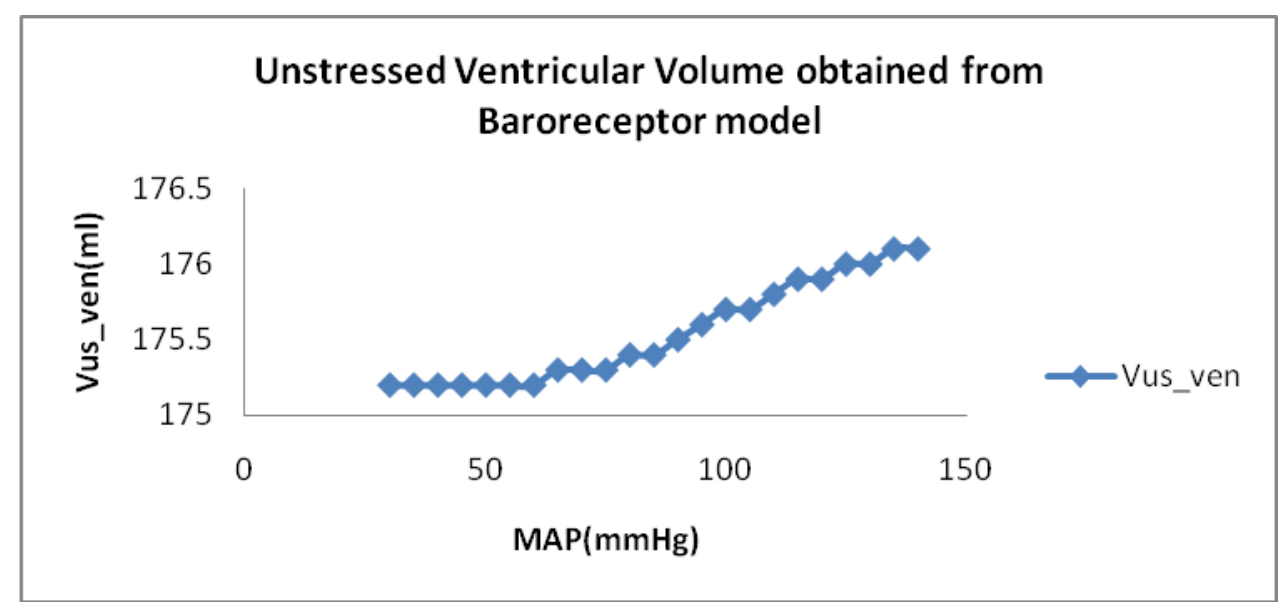

Fig. 4 V us_ven values obtained from baroreceptor model for various MAP 


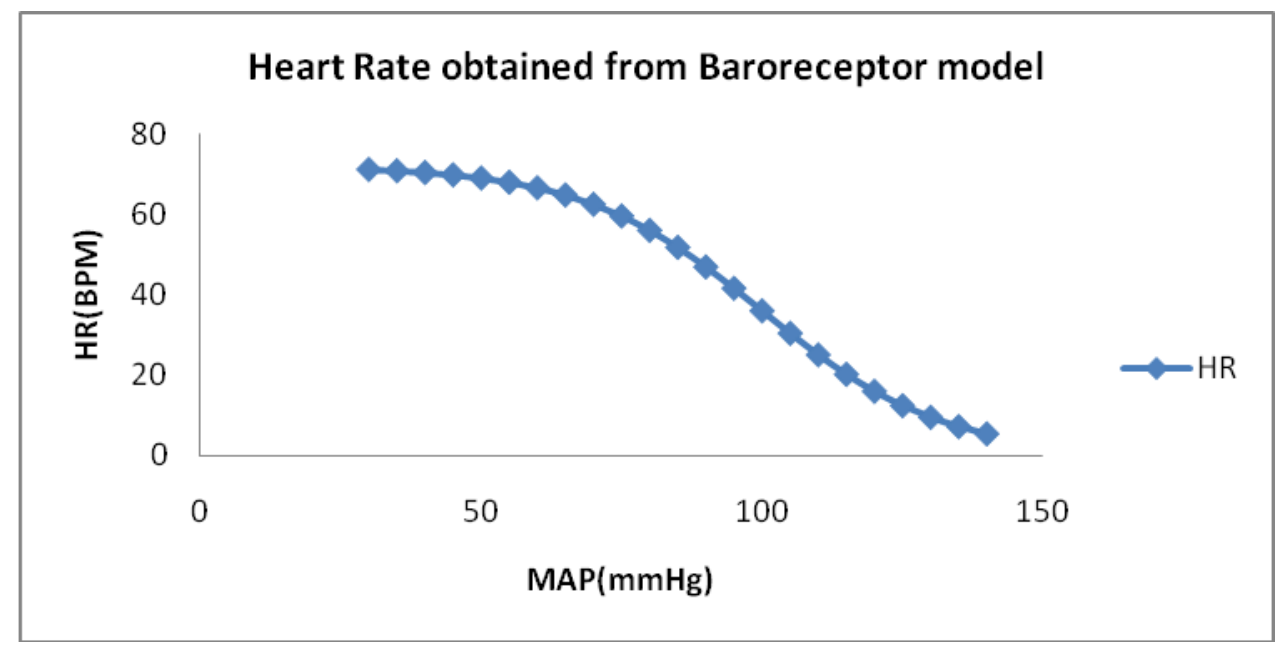

Fig. 5 HR values obtained from baroreceptor model for various MAP

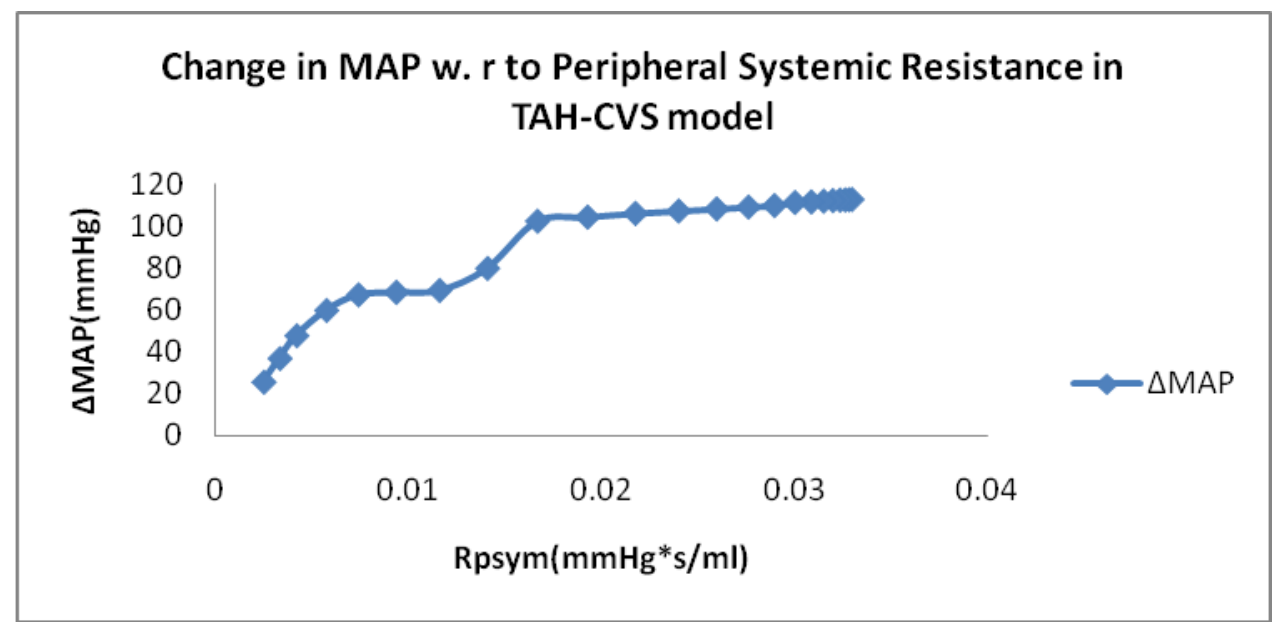

Fig. $6 \triangle$ MAP values obtained for $\mathbf{R}_{\text {psym }}$ from baroreceptor model

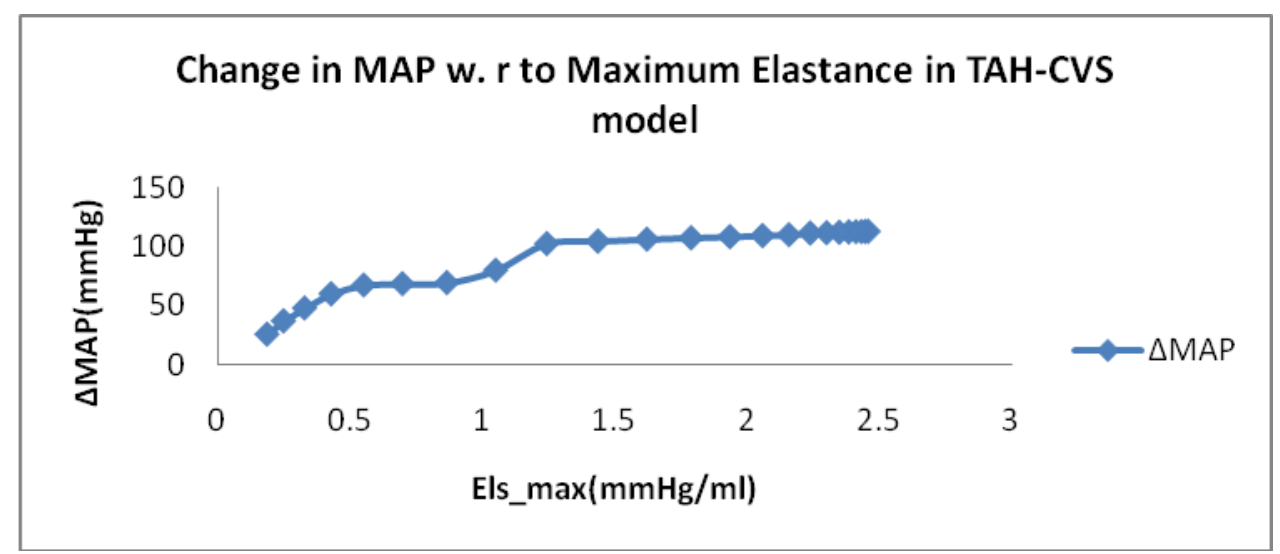

Fig. 7 MAP values obtained for Elsmax from baroreceptor model 
A Critique on Baroreceptor and their Effective Reflex Action on Compartmental Cardiovascular Modeling in Regulating Hemodynamic Parameters

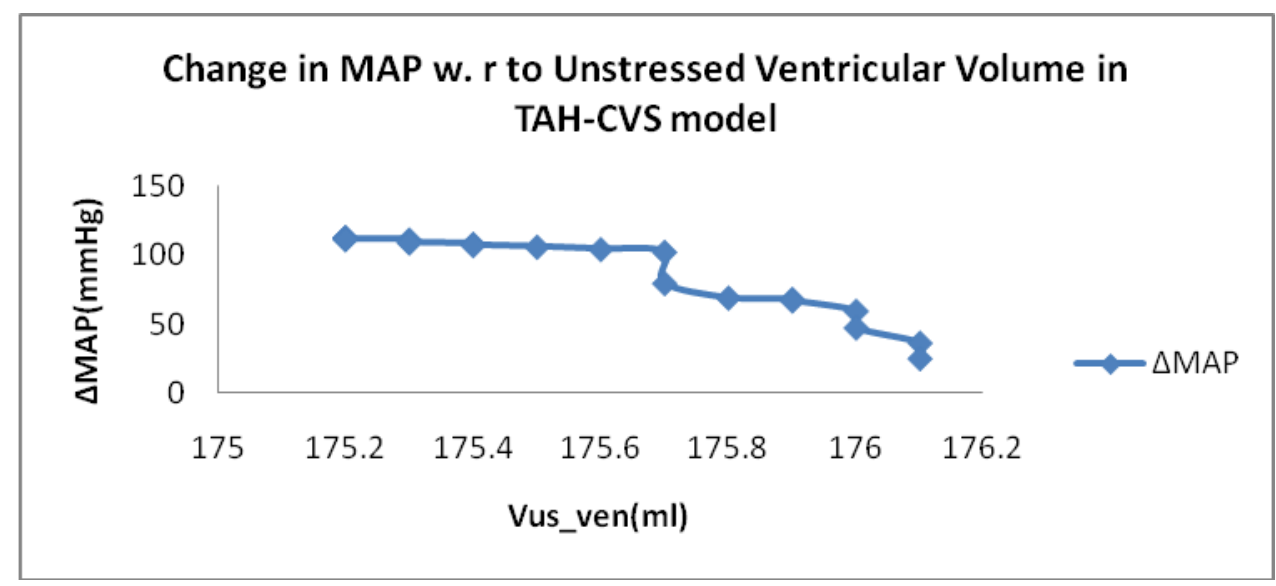

Fig. $8 \triangle$ MAP values obtained for $V_{\text {us_ven }}$ from baroreceptor model

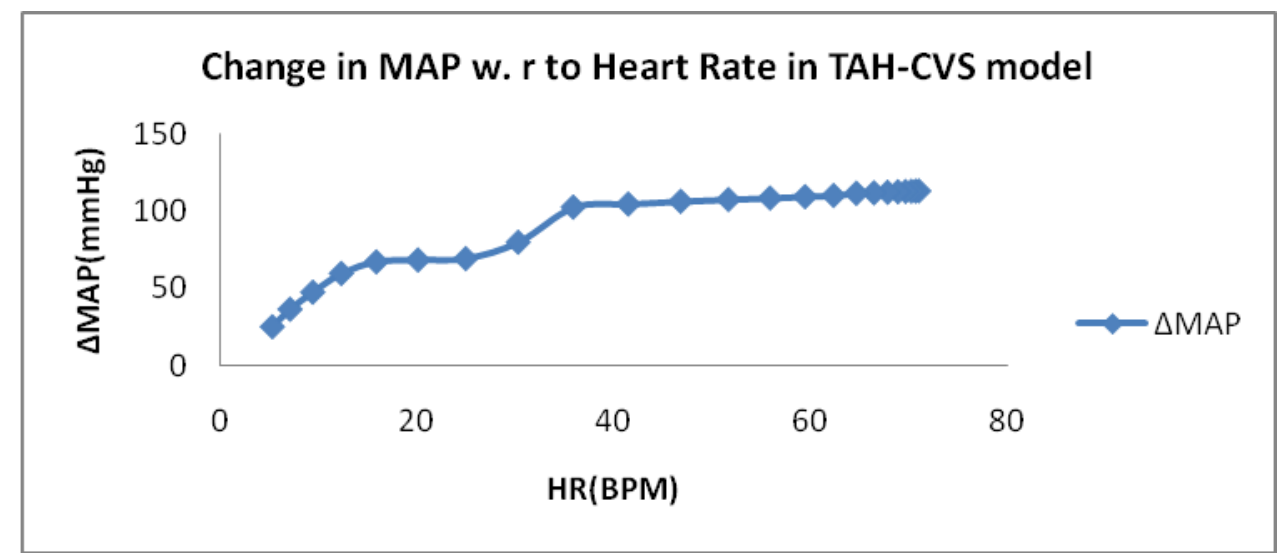

Fig. 9 MMAP values obtained for HR from baroreceptor model

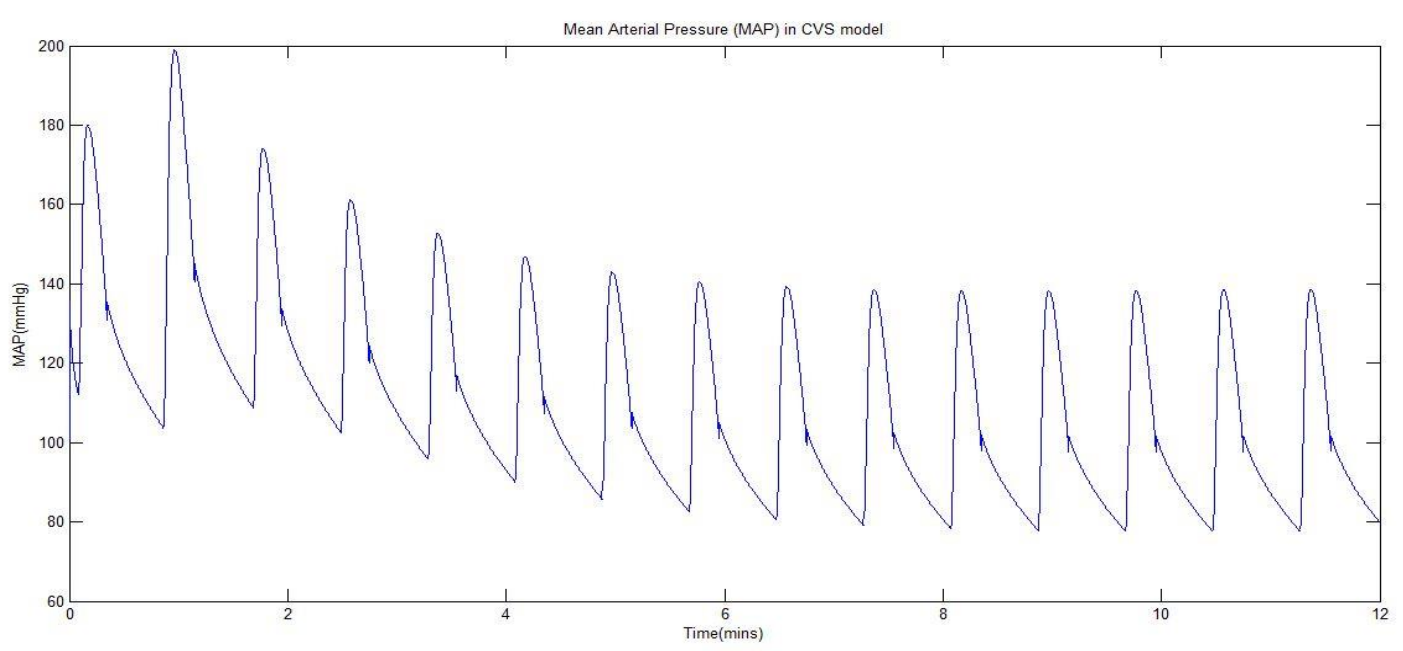

Fig. 10 Simulink result of MAP at initial condition of TAH-CVS model 


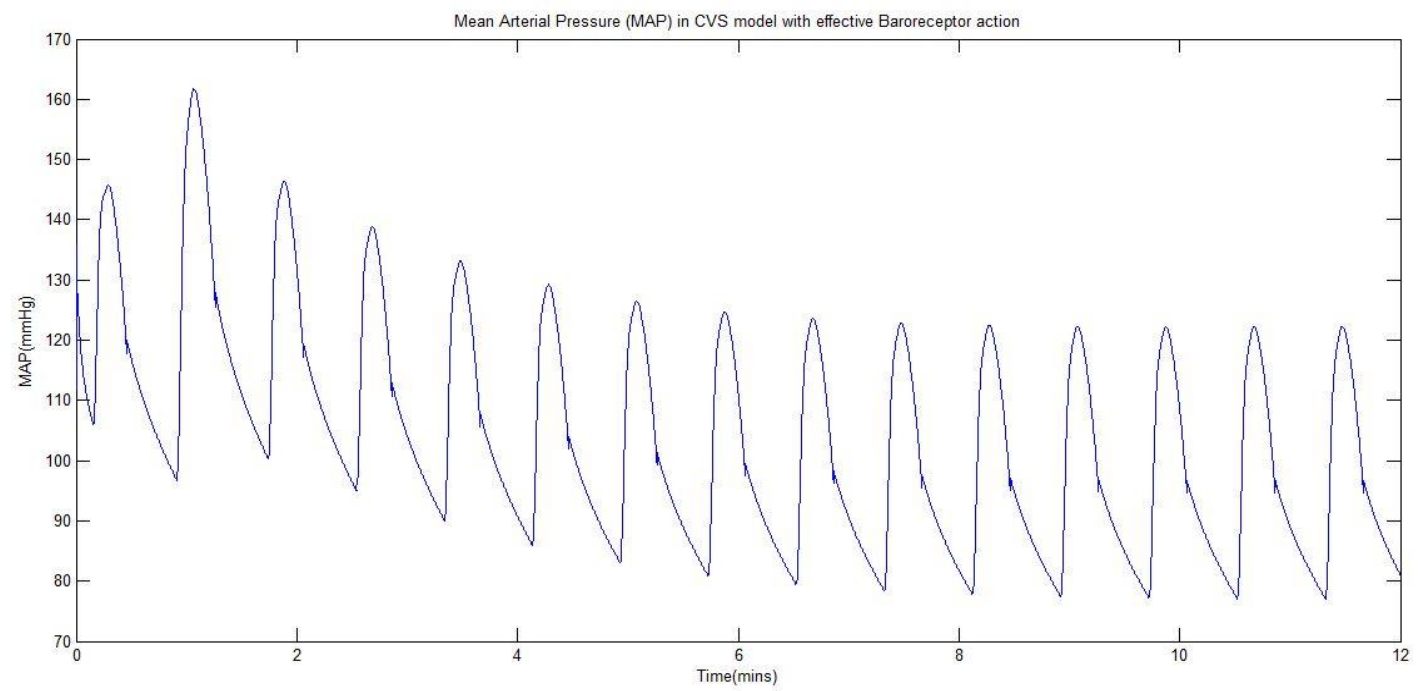

Fig. 11 Simulink result of MAP in TAH-CVS model by concurrent baroreflex action

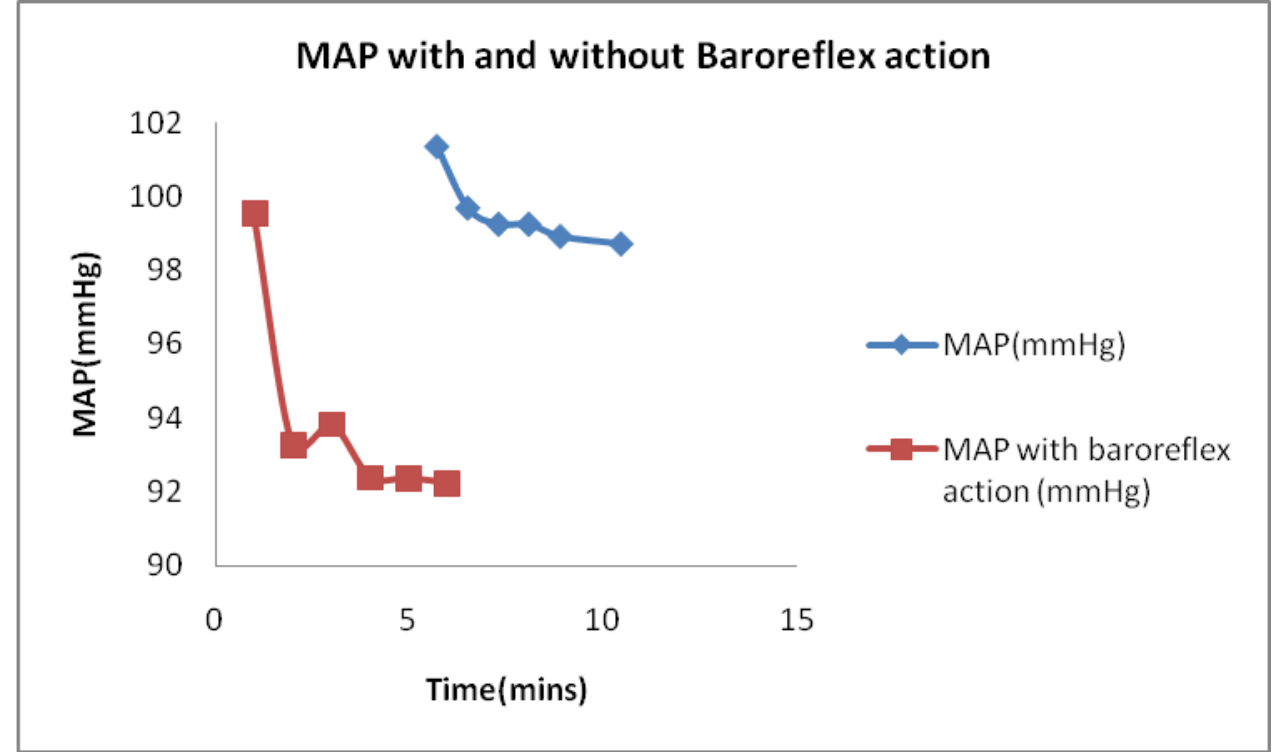

Fig. 12 Correlative analysis of MAP with and without baroreceptor in TAH-CVS model

\section{Tables}

Table I Nominal values of the circulatory system parameters

\begin{tabular}{|c|c|}
\hline PARAMETERS & NOMINAL/BASE VALUES \\
\hline$\alpha$ & 0.067 \\
\hline$M A P_{\text {nom }}$ & $100 \mathrm{mmHg}$ \\
\hline$R_{\text {psym base }}$ & $0.0334 \mathrm{mmHg}{ }^{*} \mathrm{~s} / \mathrm{ml}$ \\
\hline$E l s_{\text {max }}$ & $2.49 \mathrm{mmHg}$ \\
\hline
\end{tabular}


A Critique on Baroreceptor and their Effective Reflex Action on Compartmental Cardiovascular Modeling in Regulating Hemodynamic Parameters

\begin{tabular}{|c|c|}
\hline$V_{\text {us_ven base }}$ & $175.549 \mathrm{ml}$ \\
\hline$H R_{\text {base }}$ & $72 \mathrm{BPM}$ \\
\hline
\end{tabular}

Table II Circulatory system parameters obtained from baroreceptor model for MAP as input

\begin{tabular}{|c|c|c|c|}
\hline $\begin{array}{c}\text { PERIPHERAL } \\
\text { SYSTEMIC } \\
\text { RESISTANCE }\left(\mathbf{R}_{\text {psym }}\right) \\
\text { mmHg*s } / \mathbf{m l}\end{array}$ & $\begin{array}{l}\text { MAXIMUM } \\
\text { ELASTANCE } \\
\left(\text { Els }_{\max }\right) \mathbf{m m H g}\end{array}$ & $\begin{array}{c}\text { UNSTRESSED } \\
\text { VENTRICULAR } \\
\text { VOLUME }\left(\mathrm{V}_{\text {us_ven }}\right) \mathrm{ml}\end{array}$ & $\begin{array}{r}\text { HEART } \\
\text { RATE (HR) } \\
\text { BPM }\end{array}$ \\
\hline 0.03299 & 2.459 & 175.2 & 71.11 \\
\hline 0.03284 & 2.448 & 175.2 & 70.79 \\
\hline 0.03264 & 2.433 & 175.2 & 70.36 \\
\hline 0.03237 & 2.413 & 175.2 & 69.77 \\
\hline 0.032 & 2.386 & 175.2 & 68.99 \\
\hline 0.03152 & 2.35 & 175.2 & 67.94 \\
\hline 0.03088 & 2.302 & 175.2 & 66.56 \\
\hline 0.03004 & 2.24 & 175.3 & 64.77 \\
\hline 0.02897 & 2.16 & 175.3 & 62.46 \\
\hline 0.02763 & 2.06 & 175.3 & 59.56 \\
\hline 0.02598 & 1.937 & 175.4 & 56 \\
\hline 0.02401 & 1.79 & 175.4 & 51.77 \\
\hline 0.02177 & 1.623 & 175.5 & 46.92 \\
\hline 0.01929 & 1.438 & 175.6 & 41.59 \\
\hline 0.0167 & 1.245 & 175.7 & 36 \\
\hline 0.01411 & 1.052 & 175.7 & 30.41 \\
\hline
\end{tabular}

\begin{tabular}{|c|c|c|c|}
\hline 0.01163 & 0.8674 & 175.8 & 25.08 \\
\hline 0.009386 & 0.6997 & 175.9 & 20.23 \\
\hline 0.007423 & 0.5534 & 175.9 & 16 \\
\hline 0.005772 & 0.4303 & 176 & 12.44 \\
\hline 0.004426 & 0.33 & 176 & 9.541 \\
\hline 0.003356 & 0.2502 & 176.1 & 7.234 \\
\hline 0.002522 & 0.188 & 176.1 & 5.436 \\
\hline
\end{tabular}

